\title{
Current Issues Surrounding the Screening of Commercial Motor Vehicle Drivers for Obstructive Sleep Apnea
}

\author{
Jim Napoli ${ }^{1}$, Michele Mouttapa ${ }^{1}$, and Ben D. Buchholtz ${ }^{2}$ \\ ${ }^{1}$ California State University, Fullerton \\ ${ }^{2}$ Ben D. Buchholz, M.D., Otolaryngology
}

Each year, approximately 400,000 commercial motor vehicle (CMV) accidents occur on U.S roadways. Truck accidents represent a significant portion of these accidents, as they account for approximately 12 percent of all traffic accident fatalities (USDOT, Federal Motor Carrier Safety Administration, 2013). The prevention of accidents involving CMVs is a large public safety concern, since: (1) CMV drivers are licensed to operate commercial passenger vehicles and vehicles that may contain hazardous chemicals, and (2) there is a much higher fatality risk for individuals in vehicles that are accidentally struck by larger CMVs (National Highway Traffic Safety Administration, 2002). Within the public safety concern of CMV accidents exists a public health concern- the health of CMV truck drivers. Truck drivers are known to have higher rates of obstructive sleep apnea (OSA) compared to the general population. This condition is related to other health-related morbidities, as well as fatigue that can result in traffic accidents.

Recognizing the seriousness of OSA prevalence among CMV drivers, the Federal Motor Carrier Safety Administration (FMCSA) itself initiated a bill that unanimously passed the U.S. Senate. The bill requires the formal rule-making process to be followed regarding OSA screening, testing, and treatment of CMV drivers. It forbids the issuing of any informal guidance on this subject outside of the regulatory, rule-making process (GPO, 2013). Although the bill does not require the FMCSA to conduct mandatory screening, it allows for various experts to provide valuable data and input for the United States Department of Transportation (USDOT) to consider in developing its regulations. A formal rule-making will also require an analysis of the benefits and costs of regulating the issues of OSA diagnosis and treatment, an analysis not required for the issuance of guidance.

This editorial provides a general overview of symptoms, risk factors, consequences, and treatments for OSA, as well as how the new legislation may impact OSA screening and treatment for CMV drivers and applicants.

\section{Obstructive Sleep Apnea (OSA), Traffic Accidents, and Treatment}

OSA involves interruptions of respiratory air flow and transient hypoxia during sleep, which disrupts and fragments the sleep pattern. People with untreated OSA may not be aware of their poor sleep quality, and this condition often leads to daytime sleepiness (USDOT, NHTSA, 2013). OSA is somewhat more common among males than among females, and typical OSA patients tend to be overweight with a large neck size, middle aged or older, and a history of loud snoring. Consistent with these OSA risk factors, CMV drivers generally male, have relatively high rates of obesity, and are older (Pack, et al., 2002). In fact, OSA is far more prevalent among commercial motor vehicle (CMV) drivers (20\%$50 \%)$ as compared to the general driving population (3\%-9\%) (Pack, Dinges, \& Maislin, 2002).

Undiagnosed sleep-disordered breathing, ranging from habitual snoring to repeated breathing interruptions, increases the likelihood of crashes in a dose-response manner (USDOT, NHTSA, 2013). OSA patients have a twofold to sevenfold increased risk of at-fault motor vehicle crashes (Young, Blustein, Finn, et al. 1997). Furthermore CMV drivers with obstructive sleep apnea (OSA) have more accidents than CMV drivers without OSA (Tregear, Reston, Schoelles, \& Phillips, 2009). 
The good news is that OSA can be treated with a very high success rate. The most common therapy is a continuous positive airway pressure (CPAP) medical device that is used during sleep (George, 2001). CPAP equipment treats OSA by splinting open the upper airway during sleep with positive airway pressure applied through a facial or nasal mask via a hose connection. When the CPAP device is used correctly and every night, patients' sleep can become more normalized in nearly all cases, which results in normal daytime functioning and alertness needed for safe driving. Full compliance with CPAP treatment procedures is approximately 80\% (George, 2001; Weaver et al., 2007).

\section{Current Screening Requirements for OSA among CMV Drivers}

Both the USDOT and the California Department of Motor Vehicles require that CMV drivers undergo a thorough medical examination every two years to screen for physical and mental health that can impair driving abilities (California Department of Motor Vehicles, 2013). The only OSA screening information obtained from CMV driver applicants during the medical examination is a single self-report survey question which asks whether or not the respondent currently has an existing diagnosis of a sleep disorder, or experiences daytime fatigue (California Department of Motor Vehicles, 2013). In other words, the California CMV driver medical examination contains no objective screening criteria for potential OSA.

CMV driver applicants who screen positively for potential OSA become candidates for objective testing for OSA with diagnostic polysomnography (PSG). This diagnostic test is costly, as it evaluates disordered breathing during sleep and allows for objective diagnosis of OSA and characterization of the severity of any OSA.

\section{Recommended Screening Requirements for OSA among CMV Drivers}

Due to the significant accident risk among CMV drivers with undetected and untreated OSA, criteria for objective screening of CMV drivers (e.g., neck circumference, blood pressure and body mass index, (BMI)) for possible OSA was established in 2006 by a task force of pulmonary, occupational, environmental, and sleep medicine experts (Hartenbaum et al., 2006). The new, objective OSA screening criteria developed by the task force has high predictive validity for formal OSA diagnosis among CMV driver applicants (Talmage et al., 2008) as well as CMV drivers (Parks et al., 2009; Gurubhagavatula et al., 2004). Also other objective risk factors, such as hypertension, obesity, diabetes, has a higher predictive validity for formal OSA diagnosis among CMV drivers (Xie et al., 2011).

\section{Benefits and Barriers to OSA Treatment}

Since OSA is a very treatable medical condition, the recommendation to objectively screen CMV driver and CMV driver applicants for OSA appears eminently reasonable. The potential benefits of mandatory OSA screening for at-risk drivers are great. In a Department of Transportation report, fatigue was reported as a factor in $13 \%$ of large truck crashes (U.S. Department of Transportation, 2012). While not all driving fatigue is due to OSA, OSA screening would have the likelihood to reduce driver fatigue, and thus potentially reduce CMV accidents. Also, treating these drivers with undiagnosed OSA might have a benefit in ameliorating medical conditions associated with OSA, such as hypertension, diabetes, obesity and cardiovascular disease.

Despite the apparent benefits of mandatory objective OSA screening, there are logistical and financial implications to establishing a mandatory OSA screening program for all CMV drivers. A significant percentage of CMV drivers, perhaps even the majority of them, would not pass the initial screening and would need follow-up PSG diagnostic testing, given the fact that the prevalence of CMV drivers with undetected OSA is 20\%-50\% (Pack et al., 2002). Employers would need to decide whether or not to pay for the cost of diagnostic testing and CPAP treatment for their current drivers who screen positive. Meanwhile these drivers will lose substantial income, as they will not be able to drive until they receive documentation that either rules out an OSA diagnosis or that he or 
she has been successfully treated for OSA. Driver applicants who screen positive for OSA need to pay for diagnostic testing and treatment themselves; a lack of medical insurance is often a barrier for driver applicants to be fully evaluated and treated for OSA (Talmage, et al. 2008; Parks, et al. 2009). Furthermore those drivers and driver applicants who pass the objective OSA screening will be expected to continuously meet the minimum BMI standards to renew their certification every two years.

\section{To Screen or Not to Screen?}

Because objective screening for OSA is not yet a law at a state or federal policy level, the CMV driver population contains drivers with undiagnosed and/or untreated OSA. We support mandatory OSA screening by medical examiners for all CMV drivers (relying upon the guidelines described by Hartenbaum et al., 2006 for establishment of regulations). Increasing health insurance coverage among the general population under the Affordable Care Act (ACA) may prove beneficial for those CMV driver applicants who require follow-up diagnostic testing and possible treatment for OSA. However at this time the extent to which such health insurance will cover OSA diagnostic testing and treatment is not completely known.

Based upon what has been very recently accomplished in the aviation industry, overcoming barriers to mandatory screening of OSA among CMV drivers may be feasible.

\section{The Federal Aviation Administration (FAA)}

On November 20, 2013, the medical director of the Federal Aviation Administration (FAA) issued guidance regulations that objective OSA screening will be mandatory for all commercial pilots and air traffic controllers (U.S. Department of Transportation, Federal Aviation
Administration, 2013). BMI and neck circumference thresholds are to be used for screening for OSA with further testing and treatment, as needed. In this memo delineating these regulatory changes, the FAA medical director indicated that OSA has significant safety implications ranging from excessive daytime sleepiness to personality disturbances, cognitive impairment and sudden cardiac death. The administrative details for the implementation of this FAA policy change are pending at this time. Unlike the FMCSA, the FAA is allowed to use guidance without undergoing a formal rule-making process.

\section{Conclusion}

The commercial trucking industry maintains that testing alone for obstructive sleep apnea of truck drivers could cost the industry nearly $\$ 1$ billion (ATA, 2013). The financial burden for OSA testing and treatment will likely be borne by the self-employed CMV driver, as well as, by the commercial trucking industry. It is expected that the commercial trucking industry would take the position that the anticipated expense of OSA screening and treatment would create difficulties in recruiting and retaining employed CMV drivers and places an undue burden on independent, self-employed CMV drivers.

It is likely that the federal rule-making process will slow the establishment of guidelines at the national level for OSA diagnosis and treatment among CMV drivers. Nonetheless, and despite the formidable hurdles of the federal rulemaking process, it is our opinion that federally mandated screening of CMV drivers for OSA with subsequent treatment as needed is necessary and should be implemented without delay as a national policy matter of public safety.

(C) 2013 Californian Journal of Health Promotion. All rights reserved. 


\section{References}

American Trucking Association (ATA), (2013). ATA Applauds House Committee Passage of Sleep Apnea Bill. Washington, DC: S. McNally. Retreived from:

http://www.truckline.com/article.aspx?uid=a246bcc5-7f62-4d53-ba71-658ff38b7fb3

California Department of Motor Vehicles, CDL Unit, (2013). Medical Examination Report - DL 51. Sacramento, CA: Retrieved from: http://apps.dmv.ca.gov/forms/dl/dl51.pdf

George, C. (2001). Reduction in motor vehicle collisions following treatment of sleep apnea with nasal CPAP. Thorax, 56, 508-512. Retrieved from: http://www.bastropsleeplab.com/docs/autoaccidents02.pdf

Gurubhagavatula, I., Maislin, G., Nkwuo, J., \& Pack, A. (2004). Occupational screening for obstructive sleep apnea in commercial drivers. American Journal of Respiratory and Critical Care Medicine, 170(4), 371-376. Retrieved from: http://rmaoem.org/Pdf\%20docs/Occ\%20scrng\%20for\%20OSAcomm\%20drvrs.pdf

Hartenbaum, N., Collop, N., Rosen, I., Phillips, B., George, C., Rowley, J., \& Freedman, N. (2006). Sleep apnea and commercial motor vehicle operators: Statement from the joint task force of the American College of Chest Physicians, the American College of Occupational and Environmental Medicine, and the National Sleep Foundation. Chest, 130(3), 902-905. Retrieved from: http://journal.publications.chestnet.org/article.aspx?articleID=1084693\#ExecutiveSummary

Pack A, Dinges D., \& Maislin G. (2002). A study of prevalence of sleep apnea among commercial truck drivers. Federal Motor Carrier Safety Administration Publication No. DOT-RT- 02-030, Washington, DC. Retrieved from: http://www.fmcsa.dot.gov/safety-security/sleepapnea/industry/Commercial-Drivers.aspx

Parks, P., Durand, G., Tsismenakis, A., Vela-Bueno, A., \& Kales, S. (2009). Screening for obstructive sleep apnea during commercial driver medical examinations. Journal of Occupational and Environmental Medicine, 51(3), 275-282. Retrieved from: http://lindelisa.com/downloads/for_physicians/clinical_evidence/screening.pdf

Talmage, J., Hudson, T., Hegmann, K., \& Thiese, M. (2008). Consensus criteria for screening commercial drivers for obstructive sleep apnea: Evidence of efficacy. Journal of Occupational Environmental Medicine, 50, 324-329. Retrieved from: http://rmaoem.org/Pdf\%20docs/OSA\%20and\%20drivers.pdf

Tregear, S. Reston, J., Schoelles, K., \& Phillips, B. (2009). Obstructive sleep apnea and risk of motor vehicle crash: Systematic review and meta-analysis. Journal of Clinical Sleep Medicine, 5(6), 573-581. Retrieved from: http://www.ncbi.nlm.nih.gov/pubmed/20465027

United States Department of Transportation (USDOT), Federal Motor Carrier Safety Administration (FMCSA). (2013). Commercial Motor Vehicle Facts, Washington, DC: Retrieved from: http://www.fmcsa.dot.gov/facts-research/facts-figures/analysis- statistics/cmvfacts.htm

United States Department of Transportation (USDOT), Federal Motor Carrier Safety Administration (FMCSA). (2012). The Safety Performance of Passenger Carrier Drivers, Washington, DC: Retrieved from: http://www.fmcsa.dot.gov/facts-research/research-technology/report/12-002Bus-Driver-Safety_The-Safety-Performance-of-Passenger-Carrier-Drivers-508.pdf

United States Department of Transportation, National Highway Traffic Safety Administration. (2002). Traffic safety facts 2001. Publication DOT HS 809484 (Dec 2002). Washington, DC: Retrieved from: http://www-nrd.nhtsa.dot.gov/Pubs/TSF2001.PDF

United States Department of Transportation, National Highway Traffic Safety Administration (NHTSA). (2013). Drowsy driving and automobile crashes. Washington, DC: Retrieved from: http://www-nrd.nhtsa.dot.gov/Pubs/TSF2001.PDF

Unites States Department of Transportation (USDOT). (2012). Report to Congress on the large truck crash causation study. Washington, DC: Retrieved from: http://www.fmcsa.dot.gov/factsresearch/research-technology/report/ltccs-2006.pdf 
United States Government Printing Office (GPO). (2013). Commercial motor vehicle operator requirements relating to sleep disorders. Washington, DC: Retrieved from: http://www.gpo.gov/fdsys/pkg/BILLS-113hr3095enr/pdf/BILLS-113hr3095enr.pdf

United States Federal Aviation Administration (FAA), (2013). The Federal Air Surgeon's Medical Bulletin, New Obstructive Sleep Apnea Policy, Vol. 51, No. 4. Washington, DC. Retrieved from:

http://www.faa.gov/other_visit/aviation_industry/designees_delegations/designee_types/a me/fasmb/media/201304_editorial.pdf

Weaver, T., Maislin, G., Dinges, D., Bloxham, T., George, C., Greenberg, H., Kader, G., Mahowald, M., Younger, J., \& Pack, A. (2007). Relationship between hours of CPAP use and achieving normal levels of sleepiness and daily functioning. Sleep, 30(6): 711-719. Retrieved from: http://www.ncbi.nlm.nih.gov/pmc/articles/PMC1978355/

Xie, W., Chakrabarty, S., Levine, R., Johnson, R., \& Talmage, J. (2011). Factors associated with obstructive sleep apnea among commercial motor vehicle drivers. Journal of Occupational \& Environmental Medicine, 53(2), 169-173. Retrieved from: http://www.ncbi.nlm.nih.gov/pubmed/21270659

Young T, Peppard P., \& Gottlieb D. (2002). Epidemiology of obstructive sleep apnea: A population health perspective. American Journal of Respiratory Critical Care Medicine, 165(9), 1217-1239. Retrieved from: http://www.atsjournals.org/doi/full/10.1164/rccm.2109080\#.UpvzSqvTnIW

Young, T., Blustein, J., Finn, L., \& Palta, M. (1997). Sleepiness, driving and accidents: Sleepdisordered breathing and motor vehicle accidents in a population based sample of employed adults. Sleep, 20(8), 608-613. Retrieved from: http://www.ncbi.nlm.nih.gov/pubmed/935112

\author{
Author Information \\ *Jim Napoli \\ California State University, Fullerton \\ Department of Health Science \\ Michele Mouttapa \\ California State University, Fullerton \\ Department of Health Science
}

Ben D. Buchholz

Ben D. Buchholz, M.D., Otolaryngology

Long Beach, California

* corresponding author 